\title{
The endemic Comoros Islands fruit bat Rousettus obliviosus: ecology, conservation, and Red List status
}

\author{
Brent J. Sewall, Elise F. Granek and Will J. Trewhella
}

\begin{abstract}
Rousettus obliviosus is a megachiropteran bat endemic to the Comoros Islands in the western Indian Ocean. The species is broadly distributed on Grande Comore, Mohéli, and Anjouan, but appears to be absent from Mayotte. Roost sites were found to be both shallow and deep caves, in dark locations with infrequent human disturbance. Colony size ranged from 100 to several thousand and at two sites seasonal variation was observed. Total estimated population size was 7,100-17,100. R. obliviosus fed on a variety of native and non-native tree fruits and flowers, and was found in native forest habitats, underplanted forest and agricultural areas. $R$. obliviosus is a manoeuvrable flyer able to hover
\end{abstract}

for brief periods and may echolocate. A small range, sensitivity to disturbance, limited roost site availability and deforestation combine to threaten this species. We suggest that the current IUCN Red List status of Lower Risk: near threatened should be revised to Vulnerable. Protection of roost sites, further surveys to identify additional roosts, further ecological research, and protection of remaining forest are conservation priorities for R. obliviosus.

Keywords Comoros Islands, Megachiroptera, Red List status, Rousettus oblivious, roosts.

R. obliviosus is one of the smallest of the nine Rousettus species, with an average forearm length of $74 \mathrm{~mm}$ and a body mass of $44 \mathrm{~g}$; more detailed morphological data are available in Kock (1978), Bergmans (1994) and Reason et al. (1994). Two larger fruit bats, Pteropus seychellensis comorensis and Pteropus livingstonii, also occur in the Comoros (Bergmans, 1990).

Studies of the ecology and conservation status of R. obliviosus were called for in Mickleburgh et al. (1992) but have not been carried out until now. The species' current IUCN conservation status of Lower Risk: near threatened (IUCN, 2002) is based on extremely limited information. Here we report on observations of the roost sites, feeding ecology, and activity patterns of R. obliviosus, assess the current population size and suggest revision of the current IUCN Red List status to Vulnerable.

\section{Methods}

The distribution and foraging habitat of $R$. obliviosus was initially inferred from literature reviews and personal communications of mist-netting records of incidental captures from biologists studying nocturnal or crepuscular birds and other fruit bat species. Between 1998 and 2002 we conducted fieldwork in the Comoros to investigate the ecology and conservation status of R. obliviosus, identifying it using field characteristics that, in combination, distinguish it from other megachiropteran and microchiropteran species (Table 1). Observations 


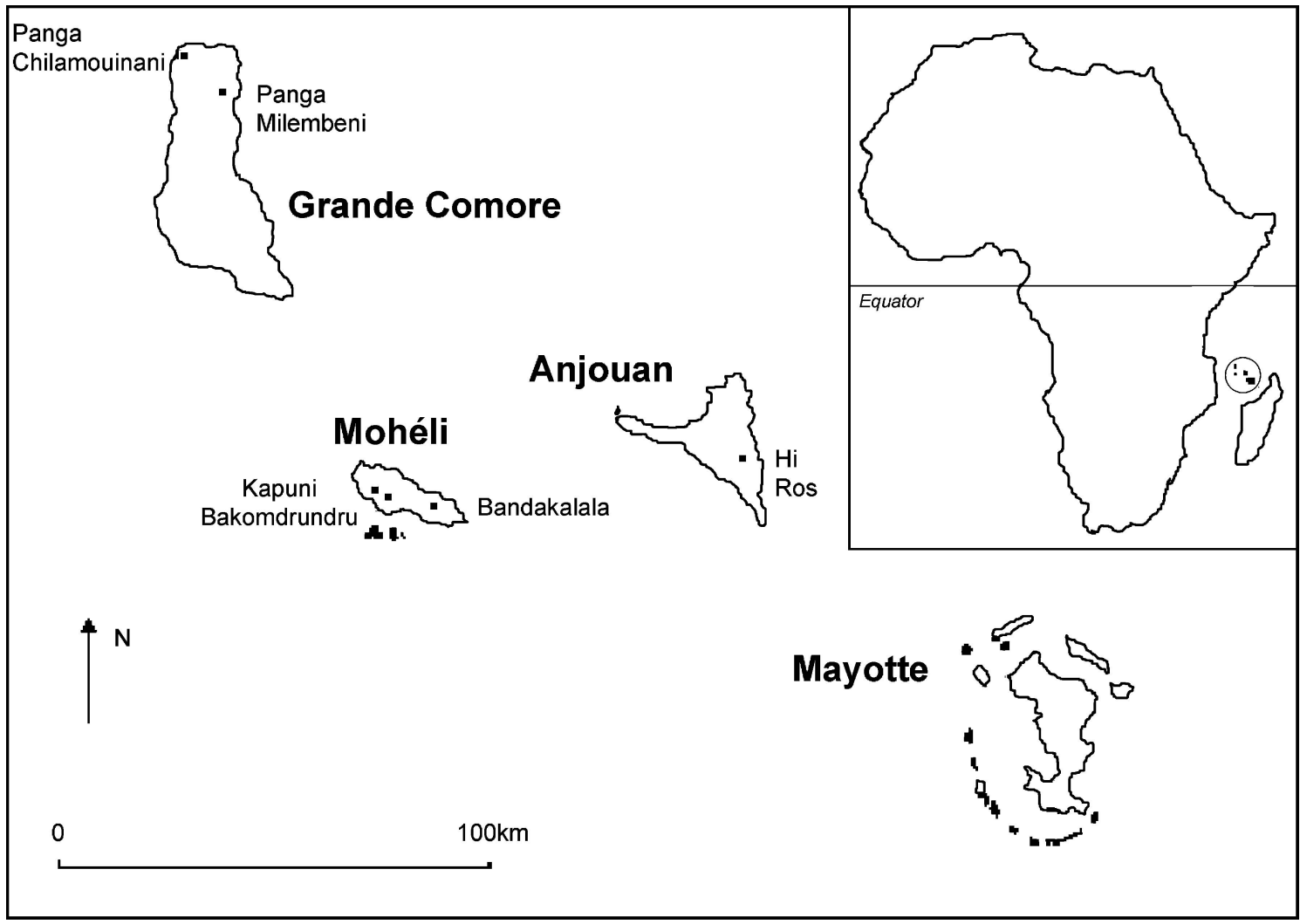

Fig. 1 The Comoros Islands, with the location of the six roost sites investigated (see text for details). The inset indicates the location of the islands in the western Indian Ocean between Madagascar and Mozambique on the south-east coast of Africa.

Table 1 Characteristics used for the field identification of Rousettus obliviosus and other bat species that occur in the Comoros, based on Cheke \& Dahl (1981), Nowak (1997) and Louette (1999).

\begin{tabular}{|c|c|c|c|}
\hline Characteristic & Pteropus species $^{1}$ & R. obliviosus & Microchiropteran bats ${ }^{2}$ \\
\hline Size & Large (wingspan >100 cm) & Mid-sized (wingspan c. $42 \mathrm{~cm}$ ) & Small (wingspan $<30 \mathrm{~cm}$ ) \\
\hline Pelage colour & $\begin{array}{l}\text { Black with red marks (P.l.), or black and } \\
\text { dark brown with yellow head (P.s.c.) }\end{array}$ & Dull grey-brown & Brownish \\
\hline Facial appearance & Fox-like & Fox-like & Microchiropteran-like \\
\hline Eyeshine & Bright & Very bright and rose-coloured & None noticeable \\
\hline Flight & Slow flapping or soaring & Fast, erratic & Fast, erratic \\
\hline Wing flapping sounds & Loud slow flaps & $\begin{array}{l}\text { Noticeable faster flaps, though } \\
\text { not loud }\end{array}$ & Not usually noticeable \\
\hline Echolocation & None & $\begin{array}{l}\text { Faint but audible clicks while } \\
\text { flying in and outside of caves } \\
\text { (see text) }\end{array}$ & $\begin{array}{l}\text { Some have audible clicks slightly } \\
\text { louder than } R \text {. obliviosus and are } \\
\text { heard in and outside of caves }\end{array}$ \\
\hline Vocalizations & $\begin{array}{l}\text { Occasional (P.l.) or frequent (P.s.c.) at } \\
\text { roosts, occasional at important foraging } \\
\text { sites, loud }\end{array}$ & $\begin{array}{l}\text { Continual and loud vocalizations } \\
\text { at roosts, occasional and fairly } \\
\text { quiet at important foraging sites }\end{array}$ & $\begin{array}{l}\text { Occasional and quiet vocalizations } \\
\text { at roosts }\end{array}$ \\
\hline Roost sites & Emergent trees & Caves or rock shelters (see text) & Caves or buildings \\
\hline Activity period & Afternoon, evening, night & Dusk, night (see text) & Dusk, night \\
\hline
\end{tabular}

${ }^{1}$ Pteropus livingstonii (P.l.)

Pteropus seychellensis comorensis (P.s.c.)

${ }^{2}$ Miniopterus minor

Myotis goudoti

Chaerephon pumilus

Taphozous mauritanius 
on Grande Comore in June and September 2001 and January 2002, on Mohéli in July - August 2000 and on Anjouan during June - August 2001 and January March 2002 were conducted by BJS. Observations on Anjouan in December 1998 and on Mohéli in January August 1999 were conducted by EFG.

Roost sites were located primarily by contacting local people in c. 30 villages. The genus Rousettus commonly roosts in caves (Nowak, 1997) and a total of seven caves, one cave system (with 10-15 adjacent and/or partially connected larger caves) and 11 shallower rock shelters on the three islands were searched for signs of roosting bats. These included reports of cave roosts for R. obliviosus on Grande Comore, near Boboni (Voeltzkow, 1906), Fassi (Middleton, 1998, 1999), and Dimadjou (Middleton, 1999) and on Anjouan near Domoni (Reason et al., 1994).

Dimensions of the roost site, aspect of the cave entrance, physical characteristics of the entrance opening and altitude were all noted or measured. Where roost caves were sufficiently shallow (on Mohéli), colony size was estimated from a vantage point outside the cave by directly counting the bats, focusing on the pink tips of their snouts when counting in low light from afar. On Grande Comore caves were entered and, standing at a distance from large colonies, headlamps were used to obtain eyeshine reflection for brief periods to allow the counting of pairs of eyes. For the two largest roost sites (Panga Chilamouinani and Bakomdrundru) it was not possible to count all bats directly but the total colony size was extrapolated based on counts of the number of individuals per cluster and the number of like-sized clusters. These daytime direct 'nose counts' and 'eyeshine counts' were considered low estimates of colony size since some areas of the cave roof were not visible. The presence or absence of microchiropteran bats at roost sites was noted and $R$. obliviosus behaviour, including social interactions, vocalizations, activity period and flight patterns, was recorded. At four roosts (Kapuni, Bakomdrundru, Panga Chilamouinani and Hi Ros) evening emergence counts (Kunz et al., 1996) were conducted from $30 \mathrm{~min}$ before sunset to $90 \mathrm{~min}$ after.

Tarpaulins were set underneath a variety of fruiting tree species prior to the foraging period of $R$. obliviosus and were checked the following morning. R. obliviosus ejecta pellets (feeding refuse) could be distinguished from those of Pteropus spp. by their much smaller overall size. Where doubt existed, the dental imprints in the pellet were examined: where the length of the imprints of three cheek teeth in a row totalled less than $9 \mathrm{~mm}$, these were considered to have come from R. obliviosus (Sewall, 2002). The tree species origin of ejecta pellets was determined based on the location of the tarpaulin in which they were found, texture and colour of the pellet and presence of seeds and other plant parts in the pellet.

\section{Results}

Incidental mist netting recorded R. obliviosus on Grande Comore, Mohéli, and Anjouan (Table 2) but not on Mayotte (Louette, 1999; F. Barthelat, pers. comm.; M. Louette, pers. comm.; E. Pasquet, pers. comm; K. RodríguezClark, pers. comm.). R. obliviosus has been recorded in forest, underplanted forest and agricultural areas (Table 2) but not in villages or towns. Altitudes of captures were 30-1,750 m on Grande Comore, 20-697 m on Mohéli and 200-1,350 m on Anjouan.

Most local residents contacted were unaware of the presence of $R$. obliviosus or confused the species with microchiropteran bats. However, four roost sites on Mohéli and Anjouan (Table 3) were found as a result of consultations with some residents who spent considerable time in the forest. Two roost sites on Grande Comore (Table 3) described by Middleton (1998, 1999) were confirmed. There was no evidence that any other caves currently had or had recently contained R. obliviosus roosts and no evidence was found of R. obliviosus roosting in locations other than caves.

The Mohéli sites were shallow caves or 'rock shelters', with a maximum distance of $3.5 \mathrm{~m}$ from the entrance to the rear of the cave. These three sites and Hi Ros on Anjouan were situated close to streams and near at least one waterfall. At each site exterior light was dim throughout the day due to the steep valley walls, dense canopy cover and the dense understorey of small trees and lianas. Each roost site was in a remote area with difficult terrain or dense vegetation and infrequently visited by people. According to several residents near Kapuni and Bandakalala, if bats were disturbed they departed and sought refuge under small rock overhangs within c. $100 \mathrm{~m}$ of the main site. One roost site (Bandakalala) had been occupied since at least 1980 (A. Boinaheri, pers. comm.) and another (Bakomdrundru) since at least 1990 (R. Soilihi, pers. comm.).

The two roost caves on Grande Comore differed markedly from those found on Mohéli, being much larger, with roosts farther from the cave entrance. Both had roosts in or just off passages extending horizontally from an entrance pit that dropped $10 \mathrm{~m}$ vertically. Both entrance pits contained thick vegetation but were surrounded by agricultural fields. Neither site was situated near water. In Panga Chilamouinani four small clusters of bats (100-400) were scattered throughout the cave and one large group $(3,000-4,000)$ was at a distance of $150 \mathrm{~m}$ from the entrance. In Panga Milembeni the roost was situated in a dark chamber above the main ceiling of the cave, c. $20 \mathrm{~m}$ from the entrance.

At all the observed roosts $R$. obliviosus formed tight single-species clusters of 50 to several hundred bats. Only Panga Chilamouinani also contained 
Table 2 Incidental captures of Rousettus obliviosus with date and location of capture, the number and sex of individuals, the altitude, habitat and the data source. Capture effort varies between studies.

\begin{tabular}{|c|c|c|c|c|c|}
\hline Capture site & Year & Number captured $^{1}$ & Altitude (m) & Habitat & Source $^{2}$ \\
\hline Unspecified (Anjouan) & 1875 & $1(\mathrm{U})$ & Unspecified & Forest & 1 \\
\hline Boboni (Grande Comore) & 1903 & $7(5 \mathrm{M}, 2 \mathrm{~F})$ & 640 & Forest & 2 \\
\hline Cercle de Bambao, Malindi (Anjouan) & 1903 & $5(\mathrm{~F})$ & Unspecified & Forest & 2 \\
\hline La Convalescence (Grande Comore) & 1981 & $2(\mathrm{U})$ & 1,750 & Forest & 3 \\
\hline La Grille (Grande Comore) & 1981 & $24(\mathrm{U})$ & 900 & Underplanted forest & 3 \\
\hline Saint Antoine (Mohéli) & 1984 & $7(\mathrm{U})$ & 697 & Forest & 3 \\
\hline Moroni - Zilimadjou (Grande Comore) & 1984 & $10(\mathrm{U})$ & 30 & Permanent subsistence cultivation & 3 \\
\hline N v̀ Tsangamouhouni (Anjouan) & 1984 & $3(\mathrm{U})$ & 200 & Permanent subsistence cultivation & 3 \\
\hline Moroni - Zilimadjou (Grande Comore) & 1986 & $2(1 \mathrm{M}, 1 \mathrm{~F})$ & 30 & Permanent subsistence cultivation & 3 \\
\hline Miringoni (Mohéli) & 1986 & $4(3 \mathrm{M}, 1 \mathrm{~F})$ & $20-50$ & Permanent subsistence cultivation & 3 \\
\hline St. Antoine (Mohéli) & 1986 & $12(3 \mathrm{M}, 9 \mathrm{~F})$ & 697 & Forest & 3 \\
\hline Malakoff (Grande Comore) & 1990 & $4(\mathrm{U})$ & 900 & Underplanted forest & 3 \\
\hline Miringoni (Mohéli) & 1990 & $2(\mathrm{U})$ & $20-50$ & Permanent subsistence cultivation & 3 \\
\hline St. Antoine (Mohéli) & 1990 & $11(\mathrm{U})$ & 697 & Forest & 3 \\
\hline La Grille (Grande Comore) & 1990 & $13(\mathrm{U})$ & 900 & Underplanted forest & 3 \\
\hline Lima Mani (Grande Comore) & 1990 & $13(\mathrm{U})$ & 1,000 & Forest & 3 \\
\hline Hasiaka (Anjouan) & 1990 & $5(\mathrm{~F})$ & 1,350 & Forest & 4 \\
\hline Madzirikini (Anjouan) & 1990 & $1(\mathrm{~F})$ & 750 & Forest & 4 \\
\hline Near Lake Dzialaoutsounga (Anjouan) & 1992 & $5(\mathrm{U})$ & 700 & Underplanted forest & 5 \\
\hline Houngouni (Anjouan) & 1992 & $20(7 \mathrm{M}, 13 \mathrm{~F})$ & 400 & Permanent subsistence cultivation & 6 \\
\hline Oimutsamudu (Anjouan) & 1992 & $138(27 \mathrm{M}, 110 \mathrm{~F}, 1 \mathrm{U})$ & 760 & Underplanted forest & 6 \\
\hline Houngouni (Anjouan) & 1993 & $46(14 \mathrm{M}, 24 \mathrm{~F}, 8 \mathrm{U})$ & 400 & Permanent subsistence cultivation & 6 \\
\hline Houngouni (Anjouan) & 1995 & $72(3 \mathrm{M}, 64 \mathrm{~F}, 5 \mathrm{U})$ & 400 & Permanent subsistence cultivation & 7 \\
\hline Dehoua River (Mohéli) & 1995 & $1(1 \mathrm{~F})$ & 30 & Underplanted forest & 8 \\
\hline Mratsini (Anjouan) & 2001 & $4(2 \mathrm{M}, 2 \mathrm{~F})$ & 880 & Forest \& underplanted forest & 9 \\
\hline
\end{tabular}

${ }^{1}$ Sex of captured bats: $\mathrm{F}=$ female, $\mathrm{M}=$ male, $\mathrm{U}=$ unspecified.

${ }^{2} 1$, Hildebrandt, cited in Kock (1978). 2, Voeltzkow, cited in Kock (1978). 3, D. Meirte, pers. comm., M. Louette, pers. comm. 4, Carroll \& Thorpe (1991). 5, R. Safford, pers. comm. 6, Young et al. (1993), Reason et al. (1994). 7, Clark et al. (1997). 8, K. Clark, pers. comm. 9, pers. obs.

microchiropterans; these roosted apart from R. obliviosus clusters. Estimated R. obliviosus colony sizes from day and emergence counts varied from 100-13,000 bats (Table 4). At Panga Chilamouinani emergence counts made during different seasons yielded considerably different colony size estimates. During two of three daytime visits to the Bandakalala roost, the colony was absent, although a few bats flew nearby during the night. Day roost count minimum estimates totalled 7,100, and emergence count estimates 7,600-17,100 (Table 4).

There was a high activity level at the roosts. At Kapuni and Bandakalala individuals were observed grooming themselves and each other, scratching, jostling for position and fighting, resulting in constant motion on the roof of the cave and frequent flights in the interior of the cave throughout the day. The colonies emitted a constant loud high-pitched 'chittering' sound.

Apart from an occasional early-departing individual, bats began leaving roost sites once daylight had disappeared from the cave area, generally a few minutes before sunset. At Panga Chilamouinani, however, departure was c. $30 \mathrm{~min}$ later and followed that of microchiropteran bats. Bats were occasionally seen returning to the roost caves after departing. During $R$. obliviosus emergence at the rock shelters, most bats circled outside the cave several times before departing, forming a large swarm during peak emergence. At Panga Chilamouinani bats circled within the entrance pit before departing. Early morning observations at Bakomdrundru revealed that hundreds of bats were already roosting by 05.00 and dozens more were circling outside the cave. Bats continued to arrive and swarm until sunrise at c. 06.15.

At roosts individuals were observed hovering for up to two seconds before landing or deciding to abort the landing attempt. A number of young were seen at Panga Chilamouinani on 15 June 2001. On three occasions at Panga Chilamouinani a barn owl Tyto alba was seen hunting microchiropteran bats as they emerged; it may also have been hunting $R$. obliviosus. During the evening $R$. obliviosus were seen flying above, at, or (more commonly) below the forest canopy level. $R$. obliviosus was manoeuvrable in flight, able to pass through tangled vines and branches in the understorey. On several occasions, both within the larger roost caves and outside the caves, faint, high-pitched clicking was heard from R. obliviosus during flight. Based on direct observations of tree visits by the bats and ejecta pellets, a list of tree species upon which the bats may feed was developed (Table 5). 


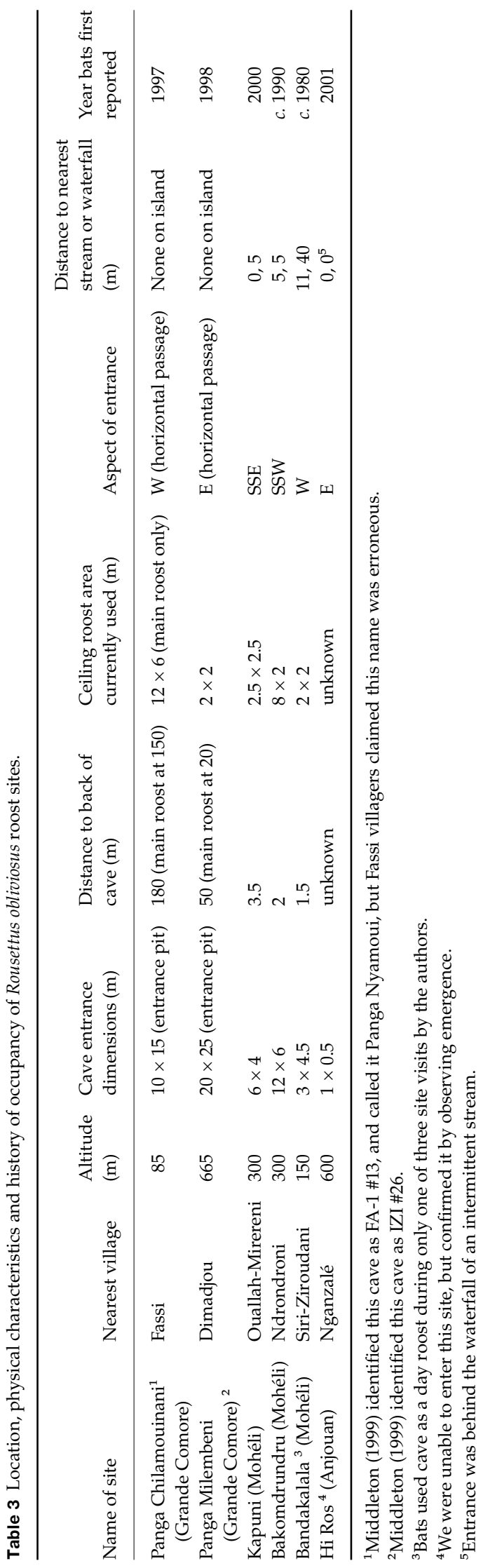


Table 4 Population estimates at Rousettus obliviosus roost sites. The day count estimate is the sum of the bats observed during daytime nose or eyeshine counts. The emergence count estimates were conducted from $30 \mathrm{~min}$ before to $90 \mathrm{~min}$ after sunset.

\begin{tabular}{|c|c|c|c|}
\hline Name of site & Day count estimate & Emergence count estimate & Date \\
\hline \multirow{3}{*}{ Panga Chilamouinani (Grande Comore) } & 3,500 & 3,500 & 15 June 2001 \\
\hline & & 13,000 & 5 September 2001 \\
\hline & & 6,800 & 22 January 2002 \\
\hline Panga Milembeni (Grande Comore) & 150 & & 16 June 2001 \\
\hline Kapuni (Mohéli) & 300 & 500 & 25 July 2000 \\
\hline Bakomdrundru (Mohéli) & 3,000 & 3,500 & 1 August 2000 \\
\hline \multirow[t]{3}{*}{ Bandakalala (Mohéli) } & 150 & & 29 June 2000 \\
\hline & 0 & 0 & 3 August 2000 \\
\hline & 0 & 0 & 15 August 2000 \\
\hline Hi Ros (Anjouan) & & 100 & 22 July 2001 \\
\hline Totals & 7,100 & $7,600-17,100$ & \\
\hline
\end{tabular}

Table 5 Likely tree species used as food sources for Rousettus obliviosus, and the evidence for usage.

\begin{tabular}{|c|c|c|c|}
\hline Tree species & Family & Resource used & Evidence \\
\hline Ceiba pentandra* & Malvaceae & Fruit \& flower & $\begin{array}{l}\text { Repeated capture near flowering trees; pollen on facial fur; } \\
\text { small ejecta pellets. }\end{array}$ \\
\hline Musa spp.* & Musaceae & Flower & Bats seen visiting trees during flowering period. \\
\hline Anthocleista grandiflora & Loganiaceae & Fruit \& flower & $\begin{array}{l}\text { Bats seen visiting trees with both fruit and flowers; small } \\
\text { ejecta pellets. }\end{array}$ \\
\hline Ficus lutea & Moraceae & Fruit & Capture near fruiting trees; small ejecta pellets. \\
\hline Ficus bojeri & Moraceae & Fruit & Small ejecta pellets. \\
\hline Ficus antandronarum & Moraceae & Fruit & Small ejecta pellets. \\
\hline Ficus pachyclada & Moraceae & Fruit & Small ejecta pellets. \\
\hline Artocarpus integrifolia* & Moraceae & Fruit & Small ejecta pellets. \\
\hline Gambeya spp. & Sapotaceae & Fruit & Capture near fruiting trees. \\
\hline Carica papaya* & Caricaceae & Fruit & Small ejecta pellets. \\
\hline Unknown & Unknown & Leaves & Small ejecta pellets. \\
\hline
\end{tabular}

*Introduced species.

\section{Discussion}

The capture and sighting records (Table 2) of Rousettus obliviosus span native and human-modified habitats and nearly the entire available altitudinal range. The absence of the Bandakalala colony during two visits and variation in emergence counts at Panga Chilamouinani may indicate seasonal variation in roost site use. Alternatively, the Bandakalala site may have been abandoned in response to disturbance.

In contrast to the tree-roosting habit of Comorian Pteropus species, all six roost sites identified were in caves. They were in dark areas infrequently disturbed by people, indicating possible roost selection criteria. There are inter-island differences in cave entrance characteristics, cave size, the type of cave (tube-like lava caves versus alcove-like rock shelters) and proximity to water. The most likely explanation for these differences is the differing availability of caves and water. Grande Comore is geologically the youngest island, with caves predominantly formed by lava flows and, unlike Anjouan and Mohéli, has no permanent running surface water (Battistini \& Vérin, 1984).

Our observations of R. obliviosus flying below, at, and above canopy level concur with incidental capture data when mist nets were set at various heights (Reason et al., 1994). In contrast, we never observed either Pteropus species flying near the ground. Another contrast is activity period: based on our observations and those of Reason et al. (1994), R. obliviosus is nocturnal, whereas the Comorian Pteropus species both exhibit significant diurnal activity (Trewhella et al., 2001).

Observations at roosts indicate $R$. obliviosus is capable of hovering briefly. Brief hovering to select food has been reported in front of flowers by Rousettus madagascariensis (P. Racey, pers. comm.) and to identify ripe fruit prior to landing by Rousettus aegyptiacus (Jacobsen \& du Plessis, 1976). Although hovering is energetically costly and observed only for a few seconds in $R$. aegyptiacus, comparisons of wing loadings and masses $\left(25 \mathrm{Nm}^{-2}\right.$, c. $130 \mathrm{~g}$ for R. aegyptiacus; $17 \mathrm{Nm}^{-2}, 44 \mathrm{~g}$ for R. obliviosus) suggest $R$. obliviosus should be capable of hovering for 
longer periods (U. Lindhe Norberg, pers. comm.). The low wing loading of $R$. obliviosus also helps to explain its observed manoeuvrability, as the radius of turn is proportional to wing loading.

Reports that some Rousettus echolocate (Pye \& Pye, 1988; Bergmans, 1994) make them unique amongst megachiropterans. Bergmans (1994) suggested that tongueclicking echolocation calls are used by all species in the genus, and our observations support this view for R. obliviosus. Visual orientation would be insufficient to reach the Panga Chilamouinani roost which is $150 \mathrm{~m}$ from the cave entrance. Our observations of faintly audible clicking from $R$. obliviosus during flight, both inside and outside of caves, coupled with reports of a similar sound emitted by captured bats just as they were released (Carroll \& Thorpe, 1991), indicate that R. obliviosus may echolocate both within cave roosts and whilst foraging.

Our observation of young at a roost in mid June, previous captures of parous and lactating females in July (Carroll \& Thorpe, 1991; Reason et al., 1994) and the discovery of an embryo in a specimen collected in October (Reason et al., 1994) indicate some variation in the timing of reproduction in $R$. obliviosus. The food resources used by $R$. obliviosus overlap with those used by the two Comorian Pteropus species (Sewall, 2002). The use of fruit, flowers, and leaves by $R$. obliviosus is also typical of R. aegyptiacus (Kwiecinski \& Griffiths, 1999).

We evaluated the conservation status of R. obliviosus based on the IUCN Version 3.1 Red List Criteria (IUCN, 2001). Three points indicate that $R$. obliviosus may be more threatened than previously believed. Firstly, the extent of occurrence (and by definition area of occupancy) is less than $2,000 \mathrm{~km}^{2}$; the combined surface area of Grande Comore, Mohéli, and Anjouan is 1,659 km² (Battistini \& Vérin, 1984). Secondly, cave-roosting fruit bats are particularly susceptible to human disturbance at roost sites (Fujita \& Tuttle, 1991), and from our observations and those of Middleton (1999) this is true for R. obliviosus. In addition, although there is no evidence of bats being hunted for food, children have been reported hunting R. obliviosus for sport at Bandakalala. Cave roofs may also be somewhat unstable; there was evidence of rockfalls in several caves (Middleton, 1998, 1999; pers. obs.). With relatively few roost sites the loss of a single site through human persecution or the collapse of a cave could seriously affect the entire population. Roost sites therefore fit the IUCN definition of "locations", areas where "a single threatening event can rapidly affect all individuals of the taxon present" (IUCN, 2001). Middleton (1998, 1999, pers. comm.) additionally surveyed more than 25 widely distributed lava caves on Grande Comore but found no large cave-dwelling bats. As the other two
Comorian megachiropteran bats do not roost in caves, we assume that $R$. obliviosus was not present in these sites. It is not known how many additional roost sites may exist on the three islands. The six known roost sites fall below the IUCN location criterion's threshold of 10 known locations. Thirdly, habitat loss is a major problem in the Comoros Islands: nearly 30\% of Mohéli's native forest disappeared between 1983 and 1996 (Moulaert, 1998) and more than $85 \%$ of Anjouan's was lost between 1972 and 1987 (Weightman, 1987).

Between 1990 and 1995 deforestation throughout the Comoros averaged 5.8\% per year, the fourth highest rate globally (Jolly \& Fukuda-Parr, 2000). Deforestation in the Union des Comores is driven by increasing needs for subsistence farmland and fuelwood (Weightman, 1987; Anon, 1998), and with a projected $2.5 \%$ annual population growth until 2015 (World Bank Group, 2000), pressures from deforestation are unlikely to ease soon. Bergmans (1994) suggested that because $R$. obliviosus forages in agricultural areas, the species may be less susceptible to the ongoing loss of native forest. However, R. obliviosus also exploits underplanted and native forest areas. The greater diversity of native forests can provide fruit bats with an increased ability to cope with seasonal and year-to-year environmental variation, including droughts and cyclones (Banack, 1998). Disturbance levels at rock shelter roost sites are also likely to increase with increasing deforestation. The use of native forest by the bats, combined with the recent observed and projected future decline of that forest, indicate that the quality of $R$. obliviosus foraging and possibly roost habitat is declining.

Our population estimates, the possibility that new roosts may be discovered, and the use of agricultural areas and non-native trees, all suggest that $R$. obliviosus is not in immediate danger of extinction. However, the small extent of occurrence, few locations and declining habitat quality are all causes for concern. We conclude that the IUCN Red List status (IUCN, 2001) of R. obliviosus is Vulnerable based on criteria B1ab(iii) $+2 \mathrm{ab}$ (iii), i.e. an extent of occurrence of $<20,000 \mathrm{~km}^{2}$ and an area of occupancy of $<2,000 \mathrm{~km}^{2}$ combined with fewer than 10 localities and a decline in the quality of habitat. In addition, based upon this status, and given its endemism, $R$. obliviosus continues to merit the highest level of species protection 'espèce intégralement protégée' (Boinali, 2001) available at a national level in the Comoros.

Limiting human activity in and around known roost sites and unexplored caves, and protecting trees and other vegetation near cave entrances should be the initial focus of conservation efforts. Trained Comorians already execute a monitoring programme for $P$. livingstonii, and therefore carrying out surveys to locate additional $R$. obliviosus sites and monitor bat numbers on a regular 
basis should be achievable. Longer-term studies on foraging behaviour, roost site requirements and population dynamics should be instigated to provide better information for the management of $R$. obliviosus. Preventing further native forest habitat loss will also be important, although harder to achieve. Small proactive steps can greatly benefit threatened species at relatively low cost. If appropriate conservation measures are taken now, we are confident that the $R$. obliviosus population can be maintained, benefiting broader biodiversity conservation in the Comoros. The national Conservation Action Plan for P. livingstonii (Sewall et al., 2003), which is nearing completion and should be implemented in late 2003, includes an appendix with an Action Plan for $R$. obliviosus. This includes a plan for monitoring and for the implementation of some of the main recommendations in this paper.

\section{Acknowledgements}

This research was made possible by financial support from Bat Conservation International, University of Minnesota MacArthur Program, Dayton-Wilkie Natural History Fund of the Bell Museum of Natural History, University of Minnesota Office of International Programs, Durrell Wildlife Conservation Trust, Bristol Zoo Gardens, British Airways Assisting Conservation, Nature Roots Group, Fauna \& Flora International, Leverhulme Trust, Richard Lounsbery Foundation, People's Trust for Endangered Species, and the Royal Geographical Society. Important logistical support was provided by Projet Conservation de la Biodiversité et Développement Durable aux Comores and Action Comores. Joseph Hawes, Ishaka Said, Abdallah Mohamed, Moustoifa Ismael, Mahamoud Madi, Soudjay Ousaine, Nadhuff Said Madi, Simon Dido, Rafiki Soilihi, Andjilane Boinaheri, Mohammed Assan, Nictoire Amir Said, Hakim Youssouf, Ismael Abu, Saïndou Moussa, Daoud Attoumane, Soyade ben Said Mardjan, and all the Mohéli Marine Park écogardes provided essential field assistance. Greg Middleton, Michel Louette, Daniel Meirte, Ulla Linde Norberg, Andrew Kitchener, Jerry Herman, Roger Safford, Moutui Mohammed and Paola Reason provided information that advanced our research. Anja Brunet, Heather York, Anthony Starfield, Diane Larson, Joseph Hawes, Michel Louette, Kathryn Rodriguez-Clark and two anonymous reviewers provided valuable comments on the manuscript.

\section{References}

Anon. (1998) U.S. in the World Fact Sheet: Connecting People and Communities to Ensure a Healthy Planet. Population Reference Bureau, Washington, DC, USA.
Banack, S.A. (1998) Diet selection and resource use by flying foxes (genus Pteropus). Ecology, 79, 1949-1967.

Battistini, R. \& Vérin, P. (1984) Géographie des Comores. Agence de Coopération Culturelle et Technique, Paris, France.

Bergmans, W. (1990) Taxonomy and biogeography of African fruit bats (Mammalia, Megachiroptera). 3. The genera Scotonycteris Matschie, 1894, Casinycteris Thomas, 1910, Pteropus Brisson, 1762, and Eidolon Rafinesque, 1815. Beaufortia, 40, 111-177.

Bergmans, W. (1994) Taxonomy and biogeography of African fruit bats (Mammalia, Megachiroptera). 4. The Genus Rousettus Gray 1821. Beaufortia, 44, 79-126.

Boinali, S.A. (2001) Arrete No. 01/31/MPE/CAB. Ministère de la Production et de l'Environnement, Moroni, République Fédérale Islamique des Comores.

Carroll, J.B. \& Thorpe, I.C. (1991) The conservation of Livingstone's fruit bat Pteropus livingstonii Gray 1866: a report on an expedition to the Comores in 1990. Dodo, Journal of the Jersey Wildife Preservation Trust, 27, 26-40.

Cheke, A.S. \& Dahl, J.F. (1981) The status of bats on western Indian Ocean islands, with special reference to Pteropus. Mammalia, 45, 205-238.

Clark, K.M., Carroll, J.B., Clark, M., Garrett, S.R.T., Pinkus, S. \& Saw, R. (1997) Capture and survey of Livingstone's fruit bats Pteropus livingstonii in the Comoros Islands: the 1995 expedition. Dodo, Journal of the Jersey Wildlife Preservation Trust, 33, 20-35.

Fujita, M. \& Tuttle, M.D. (1991) Flying foxes (Chiroptera: Pteropodidae): threatened animals of key ecological and economic importance. Conservation Biology, 5, 455-463.

IUCN (2001) IUCN Red List of Threatened Species: 2001 Categories and Criteria (v. 3.1). Http:/ /www.redlist.org/info/ categories-criteria2001.html [accessed 3 April 2003]. IUCN (2002) 2002 IUCN Red List of Threatened Species. IUCN, Gland, Switzerland [http://www.redlist.org, accessed 3 April 2003].

Jacobsen, N.H.G. \& du Plessis, E. (1976) Observations on the ecology and biology of the Cape fruit bat Rousettus aegyptiacus leachi in the eastern Transvaal. South African Journal of Science, 72, 270-273.

Jolly, R. \& Fukuda-Parr, S. (2000) Human Development Report 2000. United Nations Development Programme. Oxford University Press, New York, USA.

Kock, D. (1978) A new fruit bat of the genus Rousettus from the Comoro Islands. Proceedings of the International Bat Research Conference, 4, 205-216.

Kunz, T.H., Thomas, D.W., Richards, G.C., Tidemann, C.R., Pierson, E.D. \& Racey, P.A. (1996) Observational techniques for bats. In Measuring and Monitoring Biological Diversity: Standard Methods for Mammals (eds D.E. Wilson, F.R. Cole, J.D. Nichols, R. Rudran \& M.S. Foster), pp. 105-114. Smithsonian Institution Press, Washington, DC, USA.

Kwiecinski, G. \& Griffiths, T.A. (1999) Rousettus egyptiacus. Mammalian Species, 611, 1-9.

Louette, M. (ed.) (1999) La faune terrestre de Mayotte. Annales des Sciences Zoologiques du Musée Royal de l'Afrique Centrale, 284, 1-248.

Mickleburgh, S.P., Hutson, A.M. \& Racey, P.A. (eds) (1992) Old World Fruit Bats: An Action Plan for their Conservation. IUCN, Gland, Switzerland.

Meirte, D. (1984) De vleermuizen van de Comoren. Africa Tervuren, 30, 50-57. 
Middleton, G. (1998) Speleological survey of the lava caves of Grande Comore September 1997. Journal of the Sydney Speleological Society, 42, 201-213.

Middleton, G. (1999) Further investigations of the lava caves of the Comoros Islands - July 1998. Journal of the Sydney Speleological Society, 43, 285-309.

Moulaert, N. (1998) Etude et conservation de la forêt de Mohéli (RFI des Comores), massif menacé par la pression anthropique. $\mathrm{PhD}$ thesis, Faculté Universitaire des Sciences Agronomiques, Gembloux, Belgium.

Nowak, R.M. (1997) Walker's Mammals of the World 5.1. Online. Johns Hopkins University Press, Baltimore, USA. http:/ /www.press.jhu.edu/books/walkers-mammals-ofthe-world/prep.html [accessed 3 April 2003].

Pye D. \& Pye, A. (1988) Echolocation sounds and hearing in the fruit bat Rousettus. Advances in Audiology, 5, 1-12.

Reason, P.F., Trewhella, W.H., Davies, J.G. \& Wray, S. (1994) Some observations on the Comoro rousette Rousettus obliviosus on Anjouan (Comoro Islands: Western Indian Ocean). Mammalia, 58, 397-403.

Sewall, B.J. (2002) Fruit bat ecology and conservation in the Comoros Islands. MSc thesis, University of Minnesota, USA.

Sewall, B.J., Granek, E.F., Carroll, J.B., Feistner, A.T.C., Masefield, W., Moutui, M.F.E., Reason, P.F., RodríguezClark, K.M., Said, I., Trewhella, W.J., Vély, M. \& Wells, S. (2003) Plan d'Action pour la Conservation de la Roussette de Livingstone Pteropus livingstonii. Project Document, Projet Conservation de la Biodiversité et Développement Durable aux Comores, Moroni, Union des Comores.

Trewhella, W.J., Rodríguez-Clark, K.M., Davies, J.G., Reason, P.F. \& Wray, S. (2001) Sympatric fruit bat species (Chiroptera: Pteropodidae) in the Comoro Islands (Western Indian Ocean): diurnality, feeding interactions and their conservation implications. Acta Chiropterlogica, 3, 135-147.
Voeltzkow, A. (1906) Die Comoren. Die Erde. Zeitschrift der Gesellschaft für Erdkunde zu Berlin, 41, 606-630.

Weightman, B. (1987) The Crisis on Anjouan. Unpublished report to the Food and Agriculture Organization, Rome, Italy.

World Bank Group (2000) World Development Indicators Database 2000. The World Bank Group, Washington, DC, USA. Http:/ /www.worldbank.org/data/dataquery.html [accessed 3 April 2003].

Young, J.A., Saw, R., Trewhella, W.J. \& Cole, C. (1993) Establishing a captive breeding programme for the endangered Livingstone's fruit bat Pteropus livingstonii: the 1993 capture expedition. Dodo, Journal of the Jersey Wildlife Preservation Trust, 29, 22-33.

\section{Biographical sketches}

Brent Sewall has worked since 1993 in the US and in subSaharan Africa on population and community ecology field research, conservation of threatened species and ecosystems, and environmental education in schools and communities.

Elise Granek has taught environmental education in East and West Africa and the US, conducted field research on threatened species and ecosystems, and worked on community-based conservation.

Will Trewhella works in biodiversity education. He has a background in mammalian biology and conservation, and is co-director of the NGO Action Comores (International) which works for the conservation of the Critically Endangered fruit bat Pteropus livingstonii and its habitat in the Comoros Islands. 